\title{
Research on Body Language in Aerobics Choreography and Physical Education based on Network Questionnaire
}

\author{
Wang Bei \\ Sports Art Department, Xi'an Physical Education University, Xi'an 710068, \\ Shaanxi, China \\ wp426@126.com
}

\begin{abstract}
Network survey is a new kind of social investigation method, which is developed with the development of network technology, especially in the field of Social Science. In this paper, the author analyzes the performance of body language teaching in physical education by using network data, the result shows that students' attention, confidence and energy has increased in body language teaching. At the same time, by comparing the control group and the experimental group data, we find that movement proficiency of experience group students has increased more significant. The total score of experience group is $86.10 \pm 5.24$, while control group is $80.03 \pm 6.33$. Also, we find that the classroom atmosphere is active in the experimental group, students showed active response, high emotion, thinking more sensitive and focused attention. So that, effective use of Body language teaching will have a positive influence in physical education
\end{abstract}

Keywords: Web Survey, Body Language, Education Performance, Network Data, Aerobics Choreography

\section{Introduction}

The competition of education is one of the main competitions in the world in twentyfirst Century. In China, the basic goal of the current education is to improve the basic quality of all the students, and to cultivate the high quality talents who adapt to the changes of the new era [1]. The complexity of the rapid change of the social life and interpersonal relationship, require educators to change the traditional teaching view, teachers and students of the subject and object concept, training students ability of practice and innovation, promote the development of the overall quality of students, to become a qualified member can adapt to the social development. Body language is human activities in a special language expression form. It can not only develop students' personality, to promote the development of students' physical and mental potential and play, as well as for the cultivation of the teachers and students emotion catalyst, is also one of the ideas of teaching reform. Sports is an important part of quality education, and is an important means of quality education, it is shouldering the important duty to train the qualified personnel for the society [2]. So in the sports teaching activity using body language to explore the new ideas about the teaching of teachers, improve the art of teaching, training and development of physical and mental quality of the students, is one of the important content of quality education, is also our current PE teaching theory research and practice of physical education extremely one of an important realistic topic.

With the rapid development of science and technology and the globalization of economy, more and more people are required to develop the ability of comprehensive quality and the potential of physical and mental. Psychologists put people's potential ability can be roughly divided into two categories: physical ability and mental ability. In sports, the ability, appearance is a kind of physical ability, and in fact, it is not only physical factors, but also psychological factors. In the research and development of 
quality education, teachers should pay attention to the ability training, not only pay attention to cognitive factors, but also pay attention to the non-cognitive factors, from the intelligent center to the comprehensive development of personality[3]. Currently in China to promote the students' psychological health is still stay in the stage of general understanding, has the school sports carry out mental health education is not a fixed mode of teaching and the effective methods and means, therefore, the continuous development of adolescent psychological potential has become in their movement keep strong competition ability of key. Under the burden of impossible to advance quality-oriented education in an all-round way, impossible to implement the strategy of rejuvenating the country through science and education, only burden is to promote a profound revolution in the quality education [4]. Body language with its unique charm induction, stimulate students' multi-sensory, boring teaching becomes vivid and vigorous teaching methods, in the teaching focus on students personality and individual potential difference, reduce the burden on students' psychological stress and learning, so that every student in the day $\mathrm{Fu}$ allowed range to obtain the full development. Physical education must firmly grasp this point, to student's psychological quality training and training, let students will be stronger, so that students from inferiority become self-confident, improve students' exam, sports and social activities in the level of psychological activity, and promote the healthy growth of youth physical and mental.

With the thorough implementation of quality education, innovation education by people with unprecedented attention, the development and innovation of education has been overwhelming. In the course of teaching reform, the innovation of classroom teaching method is more urgent. For a long time, under the influence of traditional rationalism mode of education, physical education in our country formed in the teaching process of one-sided pursuit of technical movements of accuracy and norm, group teaching requirement in teaching activities obey orders and commands, degree of neglect to the student to study the interest, attitude and ability of the training, which is not conducive to the cultivation of innovative talents, is not conducive to the cultivation of students' lifelong physical attitude and ability. Sports teaching is a sound language and body language harmonization process of communication between teachers and students, the teacher's teaching art with the deepening of teaching reform, the requirements will be increasingly high, general teaching art summarized as "teaching organization, explanation and demonstration", have not kept up with the reform pace and demands. In order to adapt to the new teaching staff with innovative spirit and practical ability, innovative education should be carried out in twenty-first Centuries, and the research and practice of body language should be constantly new. Change bound education mode and method of the development of students, and strengthen the body language teaching way of teaching, so as to stimulate students' learning motivation and interest and awaken students are not aware of the potential, to enjoy and good at learning, and let the student's knowledge, ability and quality were coordinated development.

\section{Literature Review}

\subsection{Body Language Connotation}

Language, as an important tool of human communication, is built on the basis of sound. Speech is the material shell of language, and it is an important information carrier. But language is not the only means of communication. Non language body language is also a very important information carrier [5]. Related to body language and its research, English has body language, movement, gesture, behavior body, and kinesics. Some people simply use the nonverbal communication or paralanguage, kinesics instead of body language, in the discussion of specific content when there are people without distinction. These terms were classified into two types: one is the body movements in 
English kinesics, body behavior, gesture, posture language and body language belong to this class; it is another potential learning or ontology learning. Body language is the exchange of ideas, that attitude, the expression of the feelings of the information carrier, is a very complex system of symbols, it is often associated with the auxiliary speech to convey information. Non language communication is social meaning, has been or is interpreted as to send, receive is conscious, and may be fed back by the receiver, except for their use of words human attributes or behaviors. Malandro said body language refers to people using the posture change to deliver information, express their wishes, to express the form of emotional communication, it to body rhythm of non-semantic organization structure and human emotion, will direct the activities of isomorphism corresponding is a non-semantic communication form[6]. Some scholars believe that body language is produced by the body and issued with expressive function of a set of image symbols, including people's facial expressions, body posture, gestures and body position changes; it is one of the important means for human communication. Body language defined in spite of the controversial, but from the principle, seems to have consistent trend, namely body language is a carrier of information, including a mental, physical, social, ethnic, cultural and other factors, and the symbol system is by the action of the various parts of the body to feelings of human beings. It is in the form of system to the physiological changes, body movements for the constituent elements and its significance of the system is closely related with psychological mood, emotion and attitude and its functional system, social environment, behavior, sound language and other factors have close contact with.

Body language and sound language is not only the language at the beginning of the founding will contact with body language together is in any cross section of the use of language, body language are and deep-rooted language together. Specifically, from the sense of body language is a kind of special language system of visual symbols, although the "language" name, but the human general language symbol system are very different, which directly stimulates student's visual organ, vivid expressions will be presented in front of students [7]. And the sound of language is to stimulate students in auditory organs, a series of psychological activity through thinking, imagination, reasoning, judgment; it is converted to entities in their mind the significance of the image. But because of individual differences will cause the information content is attenuated and the loss in multiple passes; in terms of structure, a sound language is in a non-continuous unit basis, it is the starting point and end point of exact. Body language which is continuous, even if we stop the sound to speak, cannot stop sending information; from a functional perspective, body language cannot use language in general and independent ideographic and auxiliary generally sound language expressing the meaning, the meaning of body language vivid and expressive function of the play is often with general language to show, and semantic meaning of language in general and to enhance the language, emotion rendering. If there is no such auxiliary, general language expression effect will be seriously weakened. On the other hand, body language can only express meaning in a certain context and a kind of body language and language behavior only or other nonlanguage behavior, in order to provide clear information.

\subsection{Physical Education and Body Language}

Sports teaching is under the participation of teachers and students, sports to follow the rules, in accordance with the requirements of teaching plan and syllabus, physical and mental exercise, learning master physical knowledge, techniques and skills, cultivation of Ideological and moral quality and will a planned, purposeful, organized education process. Dynamic teaching of physical education course, different from the static conditions of the classroom teaching, the teaching and learning of their skills are operational behavior, the master of knowledge by the body to complete. Young people are the main body of the sports teaching. During this period, students have strong imitation ability, teachers in the teaching of every move will be object of student learning, imitate, norms of action 
demonstration is the direct model of student learning, to enable students to intuitively understand to learn and master the operating characteristics, structure, essentials and methods, establish a complete and correct concept of skill and movement, and can correct errors and improve the quality of the action, the theory of sports technology transformation for the practice of action and effect of the form of the body language expression in words to explain is unable to reach the.

1) Outdoor Sports Characteristics: physical activity characteristics of physical education, determine the status and value of body language in sports. Sports teaching is outside of and physiological load and psychological load is one of the special teaching process, due to the constraints of teaching objective, teaching task, teaching content, student actual situation and classroom environment, and many other conditions and in the language is different from other professional teaching, it is certain teaching purposes[8]. Due to the modern sports practice, showing broad magnificent, colorful scenes of time and space, bring the teaching space, scattered personnel mobility, activities of a wide range of characteristics, external interference factors more, in many cases transfer information more difficult, students find it difficult to control, simple to use a sound language of teaching organization, teaching knowledge and skill is not enough, therefore, when the inevitable need to play the role of language in human form, also enable the use of body language is necessary.

2) Thinking Activities: because of middle school students in PE practice lesson not positioning movement, plus some body language specific fuzzy, such as teachers of some kind of hint, a gesture, a gesture, or help, drags the size, students must seriously thinking to understand, understand the teacher's real intention. Therefore, body language teaching can not only inspire, students start to brain, effectively cultivate students' problem observation, problem analysis and problem solving ability, but also the culture and enhance the image of the students thinking, abstract thinking and creative thinking ability has important significance.

3) Atmosphere Active: The teaching process is the process of the students' intention to pay attention to the alternation of the use and the function[9]. By conscious attention to support learning will make students feel tired, difficult to lasting. Intonation and transformation of teaching that teachers are full of change of expression, cadence and rhythm, with to guide gestures or strengthen gestures, consciously transform body toward, line of sight and their spatial distance is apt to cause the students pay attention in order to become the visual center to group fabric optimization teaching effect, so as to keep the interest in learning, bring the potential of thinking, thus forming the active classroom atmosphere.

\section{Research Design}

\subsection{Methods}

1) Literature: the computer search and manual search access to the Chinese and foreign about body language and body language teaching of monographs and periodicals, especially use and learn from the education science, psychology, behavior science, linguistics related theoretical results in order to understand in this field at home and abroad research trends, and theoretical support for this study.

2) Survey: in the course of this study, visiting the experts in education, psychology, language and behavior, the relevant experts and scholars of physical education, seeking theoretical guidance. In the formulation of the questionnaire and test indicators, the experts repeatedly asked for their views and opinions, and to listen to their views and suggestions, to provide a guarantee for the smooth progress of the study. In order to obtain the 
experimental data of this study, we conducted a questionnaire survey of the students in the experimental group and the control group before and after the experiment.

3) Mathematical Statistics: the group comparison method, the experimental teaching of the pretest, post test data were input into the computer, using SPSS 11.0 statistical software for data processing and the income data were $t$ or X - test. The experiment results can be quantified, to ensure the objectivity and scientific research.

4) Experiment Method: the examination of the teaching of Aerobics teachers' pay attention to the use of body language and the performance of the frequency and the form of expression of the state of mind and aerobics class recognition, technology learning has a positive effect and effect. Students from physical education aerobics class students were randomly divided into two classes (a total of 30 people), the paired group into A, B two groups, A group for the experimental group (15 people), B group for the control group (15 people).

\subsection{The Basic Characteristics of Body Language in Physical Education}

The voice communication is composed of separate parts, remarks said, after listening to the, information exchange process ends. However, teachers in the classroom of facial expressions and eye always in the constantly changing, from beginning to end, do not have to interrupt, namely the body always intentionally or unintentionally by specific posture, movement and continue to send the information, the whole process continuous not cutting. This means that body language within a certain period of time will continuous presence. This can be proved from the persistence of vision principle. And traces of the physiological body language is continuously deep, after stimulation, such as preaching for a long time to settle in the student, the physiology of body language stimulation to react strongly, such as bona fide hits will enable the students to remember a certain action specifications, the game called "pause" gestures can be sustained visual stimuli until the command and is conducive to the students to keep attention and enhanced perceptual constancy. Therefore, no matter from the angle of the persistence of vision, or from the point of view of the brain and memory, body language reflects the timeliness of sensory motor is constant.

In sports teaching has many body language is the common use of the group, the project, the mode of action is fixed, agreed to a vulgar, and is also the objective regulations, definite the meaning of the information. And the meaning of a certain kind; it cannot be based on different situations and change the way of expression. As sports teaching and competition in micro pike nodded in honor of; single arm on Heave shown to; hands vertical offset shown suspended; arms body before the oblique lift shows normal; single punch hold high the icon collection; arms external volatiles showed dissolution; waving single blow shown adhere to the force; arms crossed in front of the chest showed exchange field. The movement of body language is entirely for the speech act of service, so it is also changing with the change of speech act, that is to say it has outstanding creative features. Can in order to illustrate some of the teaching content and advance careful design, to create special body movements, can also be oral explanation to some teaching contents according to the need to create a random; this is the teaching of temporary creative. The meaning of body language is also changing with time. Life style, cultural habits, language habits, political background of a certain era will influence the formation and change of some body language.

In sports teaching, for the specified in the teaching plan, teaching content to emphasize and repeat a language information, usually use body language give 
prominence to, to visual students to fully stimulate the, in the brains of students have deep impression, and make such an impression rise to perceptual knowledge, so as to arouse enough attention of students and to correct action the desire to imitate, enhanced student learning driving force. Such as basketball teaching teachers repeatedly dialed last act, the purpose of which is to highlight last dial refers to is the emphasis and difficulty of shooting; to highlight the characteristics of a technical action, the key aspects of the demonstration to slow down or do freeze, in order to facilitate the students to establish a clear action.

\section{Empirical Analysis}

\subsection{Emotional Experience}

From the point of view of constitution of action, a set of complete aerobics include the movement of the various parts of the body, it has type, direction, route, strength, speed of different multiple actions composition, in teaching the use of body language can also more comprehensive and complete reflected. Fitness and aerobics teaching is not only the memory of action essentials and string combination or the movements of a set of memory, like Chinese verbal memory, and other sports side for Essentials of memory. From the point of view of Professor, aerobics teaching especially popular aerobic exercises tie way, pay attention to the use of body language, the success of the tie and often determines the level of use of body language. Therefore, this paper to Aerobics Teaching in Colleges and universities, for example, in close connection with the theory of body language, to study body language research in the field of sports, empirical in the concrete teaching practice and effective through the teaching experiment. From table 1, the results showed that students in the various options for each question exist significant differences, especially in focus, self-confidence and satisfaction, energetic mood experience has significant difference $(\mathrm{P}<0.01)$, so that students in the experimental group to aerobics course of emotional experience to be significantly higher than the control group.

Table 1. The Chi Square Test of Students' Emotional Experience

\begin{tabular}{|c|c|c|c|c|c|c|c|}
\hline Problem & Group & $\begin{array}{l}\text { Very } \\
\text { good }\end{array}$ & Good & Commonly & $\mathrm{Bad}$ & $\begin{array}{l}\text { Very } \\
\text { bad }\end{array}$ & $X^{2}$ \\
\hline \multirow{2}{*}{$\begin{array}{c}\text { Nervous and } \\
\text { trouble }\end{array}$} & experience & 4 & 6 & 4 & 1 & 0 & \multirow{2}{*}{ 7.917* } \\
\hline & control & 2 & 3 & 6 & 4 & 0 & \\
\hline \multirow{2}{*}{ Lonely } & experience & 5 & 5 & 3 & 2 & 0 & \multirow{2}{*}{2.834} \\
\hline & control & 4 & 3 & 4 & 4 & 0 & \\
\hline \multirow{2}{*}{ Fatigue } & experience & 2 & 7 & 4 & 5 & 0 & \multirow{2}{*}{$8.750 *$} \\
\hline & control & 1 & 5 & 6 & 3 & 0 & \\
\hline \multirow{2}{*}{$\begin{array}{c}\text { Relaxed and } \\
\text { pleasant }\end{array}$} & experience & 6 & 5 & 3 & 1 & 0 & \multirow{2}{*}{$10.50^{*}$} \\
\hline & control & 3 & 6 & 3 & 1 & 0 & \\
\hline \multirow{2}{*}{$\begin{array}{c}\text { Attention } \\
\text { concentration }\end{array}$} & experience & 7 & 5 & 6 & 3 & 0 & \multirow{2}{*}{$17.20 *$} \\
\hline & control & 2 & 5 & 4 & 4 & 0 & \\
\hline \multirow{2}{*}{ Energetic } & experience & 6 & 6 & 2 & 1 & 0 & \multirow{2}{*}{$27.30^{*}$} \\
\hline & control & 1 & 8 & 5 & 1 & 0 & \\
\hline
\end{tabular}

From the results of the investigation as shown in table 2, we can find that control group relative to reduce the students on all aspects of the self-motion, and the experimental group can effectively improve the student evaluation in all aspects of their movements, of which action accuracy, action expression exist extremely significant difference $(\mathrm{P}<0.01)$ : experimental group students ability of self-perceived better than the control group. Table 3 shows that, the experimental group of students in aerobics class evaluation was significantly better than the control group. 
Table 2. The Chi Square Test for Students' Self-Evaluation

\begin{tabular}{|c|c|c|c|c|c|c|c|}
\hline Problem & Group & $\begin{array}{l}\text { Very } \\
\text { good }\end{array}$ & Good & Commonly & $\mathrm{Bad}$ & $\begin{array}{l}\text { Very } \\
\text { bad }\end{array}$ & $X^{2}$ \\
\hline \multirow[b]{2}{*}{ strength } & experience & 3 & 7 & 4 & 1 & 0 & \multirow[b]{2}{*}{5.200} \\
\hline & control & $\frac{3}{2}$ & 4 & 5 & 4 & 0 & \\
\hline \multirow{2}{*}{ Amplitude } & experience & 3 & 6 & 4 & 1 & 0 & \multirow{2}{*}{$8.452 *$} \\
\hline & control & 2 & 3 & 47 & 3 & 0 & \\
\hline \multirow{2}{*}{ accuracy } & experience & 5 & 7 & 2 & 1 & 0 & \multirow{2}{*}{$22.86^{*}$} \\
\hline & control & 2 & 2 & 6 & 5 & 0 & \\
\hline \multirow{2}{*}{$\begin{array}{l}\text { Action } \\
\text { memory }\end{array}$} & experience & 5 & 5 & 3 & 1 & 0 & \multirow{2}{*}{$8.550 *$} \\
\hline & control & 2 & 2 & 4 & 1 & 0 & \\
\hline \multirow{2}{*}{ Coordination } & experience & 7 & 4 & 3 & 3 & 0 & \multirow{2}{*}{5.038} \\
\hline & control & 4 & 4 & 4 & 4 & 0 & \\
\hline \multirow{2}{*}{ presentation } & experience & 5 & 7 & 2 & 1 & 0 & \multirow{2}{*}{$12.45^{*}$} \\
\hline & control & 2 & 3 & 5 & 5 & 0 & \\
\hline
\end{tabular}

Table 3. The Chi Square Test of the Degree of Recognition of the Class

\begin{tabular}{|c|c|c|c|c|c|c|c|}
\hline Problem & Group & $\begin{array}{l}\text { Very } \\
\text { good }\end{array}$ & Good & Commonly & $\mathrm{Bad}$ & $\begin{array}{l}\text { Very } \\
\text { bad }\end{array}$ & $X^{2}$ \\
\hline \multirow{2}{*}{$\begin{array}{l}\text { willing to } \\
\text { participate }\end{array}$} & experience & 3 & 8 & 3 & 1 & 0 & \multirow{2}{*}{4.433} \\
\hline & control & 2 & 7 & 3 & 3 & 0 & \\
\hline \multirow{2}{*}{$\begin{array}{l}\text { More } \\
\text { confidence }\end{array}$} & experience & 5 & 8 & 1 & 1 & 0 & \multirow{2}{*}{$23.25 * *$} \\
\hline & control & 1 & 5 & 5 & 4 & 0 & \\
\hline \multirow{2}{*}{$\begin{array}{l}\text { technical } \\
\text { skills }\end{array}$} & experience & 6 & 6 & 2 & 1 & 0 & \multirow{2}{*}{$9.333^{*}$} \\
\hline & control & 2 & 9 & 3 & 1 & 0 & \\
\hline \multirow{2}{*}{$\begin{array}{c}\text { interpersonal } \\
\text { relationship }\end{array}$} & experience & 6 & 7 & 1 & 1 & 0 & \multirow{2}{*}{$10.120^{*}$} \\
\hline & control & 2 & 7 & 4 & 2 & 0 & \\
\hline \multirow{2}{*}{ creativity } & experience & 4 & 7 & 3 & 1 & 0 & \multirow{2}{*}{11.167} \\
\hline & control & 1 & 6 & 6 & 2 & 0 & \\
\hline
\end{tabular}

In physical education, body language is permeated in every link of teaching activities, and the teaching process is always carried out. Aerobics as a particular case of sports teaching, the characteristics of the teaching content far different from other sports courses, part of the action form of exercise, it is in the accompaniment of music of a sport, music and uninterrupted, fluency and melodic beauty, teachers need under the premise that does not affect the normal students practice for students to consciously guide and correction. Students in listening to music practice situation, highlights the use of the body language, language temporarily, several, at this time the body language of teachers and students' practice, music as a whole and silent, excluding the interference of the language of music, also avoid distracting the attention of students quality, realize the consciousness of students to actively guide. Exclusive action from practice characteristics, general is technical movements and some body language activities, students learn and Practice on Teachers' body language basic synchronization is complete, the formation of threedimensional information transfer mode in information transmission and feedback with spatial and temporal immediacy, teaches in a high school, learning to practice, practice, so that the whole teaching process to maintain continuity, and does not appear disjointed phenomenon, shorten the teachers to explain or separately by the demonstration of the consumption of time, the corresponding increase in students of absorption and time of 
exercise, the better to achieve the fitness and learning effect, and truly realize the aerobics movement.

\subsection{Evaluation of Learning Effect}

From the horizontal and vertical perspective, as shown in table 4, control group and the experimental group before and after the experiment had highly significant difference that two groups of students are improved. From the difference between the two groups comparison test $(\mathrm{T}=6.480 ; \mathrm{P}<0.01)$ see, the movement technology in the experimental group than controls have more significant improvement, indicating that experimental group strengthen the use of body language more conducive to the improvement of student movement skills and improve. From the student's movement accuracy as shown in table 5, only in the experimental group pre-test and posttest accuracy with significant difference $(\mathrm{P}<0.05)$, before and after the other, inter group showed no significant difference $(\mathrm{P}>0.05)$, indicating that the experimental group understanding accuracy of the action was better than that of the control group.

Table 4. Comparison of Students' Technological Movement

\begin{tabular}{|c|c|c|c|c|}
\hline Group & $\begin{array}{c}\text { Pre } \\
\text { experimental }\end{array}$ & $\begin{array}{c}\text { Post } \\
\text { experiment }\end{array}$ & difference & $\begin{array}{c}\text { paired t- } \\
\text { test }\end{array}$ \\
\hline $\begin{array}{c}\text { experience } \\
\text { group }\end{array}$ & $78.73 \pm 7.59$ & $86.10 \pm 5.24$ & $7.37 \pm 0.92$ & $8.007 * *$ \\
\hline control group & $78.77 \pm 6.94$ & $80.03 \pm 6.33$ & $1.27 \pm 0.27$ & $4.072 *$ \\
\hline $\mathrm{t}$ test & 0.014 & $3.019^{*}$ & $6.480^{* *}$ & \\
\hline
\end{tabular}

Table 5. Comparison of Students' Motion Accuracy

\begin{tabular}{|c|c|c|c|c|}
\hline Group & $\begin{array}{c}\text { Pre } \\
\text { experimental }\end{array}$ & $\begin{array}{c}\text { Post } \\
\text { experiment }\end{array}$ & difference & $\begin{array}{c}\text { paired t- } \\
\text { test }\end{array}$ \\
\hline $\begin{array}{c}\text { experience } \\
\text { group }\end{array}$ & $16.47 \pm 1.47$ & $17.07 \pm 1.08$ & $0.60 \pm 0.26$ & $2.276^{*}$ \\
\hline control group & $16.40 \pm 1.00$ & $16.50 \pm 0.93$ & $0.10 \pm .012$ & 0.823 \\
\hline $\mathrm{t}$ test & 0.133 & 1.554 & 1.408 & \\
\hline
\end{tabular}

From the movements of the two groups, as shown in table 6, we can get that control group before and after the test no significant difference $(\mathrm{P}>0.05)$, before and after the other and between groups were compared with significant differences, especially between group difference $(\mathrm{T}=3.717 ; \mathrm{P}<0.01)$ has a highly significant difference, indicating that the experimental group students range of motion than the control group in improving. From the data as shown in table 7, we can get that the control group before and after the test there was no significant difference $(\mathrm{P}>0.05)$, before and after the other and between groups were compared with significant differences, indicating that regulation ability of the students in the experimental group action, intensity is obviously better than that of the control group. As shown in table 8, we can get that the control group pretest and posttest without significant difference $(\mathrm{P}>0.05)$, before and after the other and between groups were compared with significant difference $(\mathrm{P}<0.01)$, explain the control group of students skilled movements without significantly improved, the experimental group is on students' understanding of skilled movements of has greatly enhance the effect.

In observation, the experimental group, the classroom atmosphere more active. Students active, emotional high, thinking reaction is more sensitive, laugh more, attention, interact more, learn in this active, open and healthy psychological environment, conducive to the formation of students' emotional experience. Control group, the 
classroom atmosphere is relatively dull, students often take the initiative to exercise less, learning emotion, it is difficult to stimulate, show boredom, lazy mood, for teachers to organize the teaching without reacted strongly. Undoubtedly, students in this negative, depressed, unhealthy psychological environment to learn, is not conducive to the formation of a good emotional experience, and even easy to cause students to learn the occurrence of mental disorders.

Table 6. Comparison of Students' Motion Amplitude

\begin{tabular}{|c|l|l|l|l|}
\hline Group & Pre experimental & Post experiment & difference & paired t-test \\
\hline experience group & $15.70 \pm \mathrm{I} .77$ & $17.43 \pm 1.23$ & $1.73 \pm 0.37$ & $4.711^{* *}$ \\
\hline control group & $15.67 \pm 1.65$ & $15.87 \pm \mathrm{I} .59$ & $0.20 \pm 0.16$ & 1.193 \\
\hline $\mathrm{t}$ test & 0.071 & $2.957^{*}$ & $3.717^{* *}$ & \\
\hline
\end{tabular}

Table 7. Comparison of Students' Action Dynamics

\begin{tabular}{|c|l|l|l|l|}
\hline Group & \multicolumn{1}{|c|}{$\begin{array}{c}\text { Pre } \\
\text { experimental }\end{array}$} & $\begin{array}{c}\text { Post } \\
\text { experiment }\end{array}$ & difference & $\begin{array}{c}\text { paired } t- \\
\text { test }\end{array}$ \\
\hline experience group & $15.37 \pm 1.97$ & $17.20 \pm 1.26$ & $1.83 \pm 0.32$ & $5.821^{* *}$ \\
\hline control group & $15.50 \pm 1.50$ & $15.80 \pm 1.54$ & $0.30 \pm 0.16$ & 1.871 \\
\hline $\mathrm{t}$ test & 0.201 & $2.866^{*}$ & $3.944^{* *}$ & \\
\hline
\end{tabular}

Table 8. Comparison of Students' Movement Proficiency

\begin{tabular}{|c|l|l|l|l|}
\hline Group & \multicolumn{1}{|c|}{$\begin{array}{c}\text { Pre } \\
\text { Experimental }\end{array}$} & \multicolumn{1}{|c|}{$\begin{array}{c}\text { Post } \\
\text { Experiment }\end{array}$} & Difference & $\begin{array}{c}\text { Paired T- } \\
\text { Test }\end{array}$ \\
\hline $\begin{array}{c}\text { experience } \\
\text { group }\end{array}$ & $15.93 \pm 1.47$ & $17.40 \pm 1.99$ & $1.47 \pm 0.22$ & $6.644^{* *}$ \\
\hline control group & $15.73 \pm 1.70$ & $16.10 \pm 1.31$ & $0.37 \pm 0.20$ & 1.798 \\
\hline $\mathrm{t}$ test & 0.389 & $3.101^{* *}$ & $3.556^{* *}$ & \\
\hline
\end{tabular}

The experimental group in the teaching of the language is the use of synchronous side demonstration with language tips, in the demonstration of the use of body language at the same time, with the appropriate schematic of body language to help convey and prompt teaching contents for students to establish a more clear image and memory traces, with accurate, concise and vivid and enlightening language, makes the conversion between movements, the movement route and the movement direction is more clear to the students at the same time intensive to launch a series of mutually supporting teaching content, provides a visual and perceptual knowledge of students for students, mobilize the Visual Auditory tactile learning function, multi genre, multi perspective, multi form and multi range to express the same information, complex and thoroughly decomposed information, complicated system of simple, scattered, deep Austria is easy, the abstract to the concrete, for students to reduce cognitive burden, stimulate students' excitement on a grand scale, resonance, estrogen, make students' senses and imagination combined with each other, produce unprecedented thinking space and manufacturing resource, improve students' perception ability of action, but also to improve the students' understanding and memory efficiency, make student natural harmony into a positive state of mind, from perceptual to rational, from rationality to practice cycle and realize leap forward in the understanding. This indicates that body language is a kind of constructive behavior can promote students in physical exercise of power factors: beliefs, attitudes, and students' ability of selfperception is reality of $\mathrm{P}$. E teaching optimization and effective means. 


\section{Conclusions}

In sports teaching, body language is a constructive act, correct and effective use can help students have a positive emotional experience, can enhance the students' ability of self-perception and promote the development of students' ability in many aspects, conducive to the improvement of students' technical ability. In the comprehensive quality training and development of students, improve the teachers' teaching art, and comprehensively promote the innovation and development of education, physical and mental health of the quality education in the development and reconstruction of the new teacher-student relationship has a unique function. But everyone will do, body movements, facial expressions, and everyone, and everyone will do, everyone has expression and sports teaching consciously use body language are not exactly the same. In practical teaching, learning body language is easy to make the mistake of machinery. There will be all kinds of body language mechanically one view of one point less than the rest. Therefore, the physical education should pay attention to utilize and exert the characteristics of physical education discipline, accurate and appropriate use of body language and improve the teaching quality and effect. Inspire students' positive thinking is one of the important tasks of teachers in teaching. In sports teaching due to students not positioning movement, and body language ambiguity, making body language can activate students' brain, reached the completion of teaching tasks, to enhance students' abstract thinking, stimulate the students' enthusiasm, initiative and creativity has important significance. Physical education teachers in the implementation of the teaching process, we must constantly remind ourselves to use body language to inspire students to think actively, to make the students understand the teacher's applause, gestures, body movements, experience an action essentials, force time, force, the force direction, correct capture, understand teacher's intentions, complete teaching tasks.

Body language is an indispensable communicative activity, but it is not any kind of body language can be the classroom. The movements between various body languages to cooperate with each other, a variety of body language requirements between the coordination, in order to give people a harmonious natural beauty. Successful teachers tend to use a variety of body language in the expression of a variety of body language in the teaching to add more performance, but also smooth and natural, so as to stimulate students to more strongly visual reception system. Body language and technique characteristics, teaching style should be consistent, and integrated with the teaching content, do not apply mechanically. Body language is often accompanied by the expression of sound language, but also for the expression of sound language services, therefore, body language should be the content of the expression of sound language should be harmonious and unified. Whether in the content of the two expressions, or on time and method, they all want to be consistent, only in order to achieve their own ideas and desires, and improve the efficiency of information transmission.

\section{References}

[1] R. A. Sabella, "School counselors perceived importance of counseling technology competencies", Computers in Human Behavior, vol. 26, (2010), pp. 609-617.

[2] L. Michel and R. Mohammad, "The effects of social media based brand communities on brand community markers, value creation practices, brand trust and brand loyalty", Computers in Human Behavior, vol. 28, no. 5, (2012), pp. 1755-1767.

[3] Z. Catts, "Certified Genetic Counselors: A Crucial Clinical Resource in the Management of Patients with Suspected Hereditary Cancer Syndromes", Review, Surgical Oncology Clinics of North America, vol.24, (2015), pp. 653-666.

[4] N. R. Mastroleo and R. Turrisi, "Examination of posttraining supervision of peer counselors in a motivational enhancement intervention to reduce drinking in a sample of heavy-drinking college students", Journal of Substance Abuse Treatment, vol. 39, (2010), pp. 289-297.

[5] R. Khansa, "Teachers' Perceptions toward School Counselors in Selected Private Schools in Lebanon", Procedia-Social and Behavioral Sciences, vol. 185, (2015), pp. 381-387. 
[6] Z. Huang and M. Benyoucef, "From e-commerce to social commerce: A close look at design features", Electronic Commerce Research and Applications, vol. 12, no. 4, (2013), pp. 246-259.

[7] M. Alavi, "The Challenges of High School Counselors in Work PlaceOriginal", Procedia-Social and Behavioral Sciences, vol. 46, (2012), pp. 4786-4792.

[8] K. Anand, "Context-general and Context-specific Determinants of Online Satisfaction and Loyalty for Commerce and Content Sites", Journal of Interactive Marketing, vol. 24, no. 3, (2010), pp. 222-238.

[9] S. E. Carrell and M. Hoekstra, "Are school counselors an effective education input?", Economics Letters, vol. 125 , (2014), pp. 66-69.

\section{Authors}

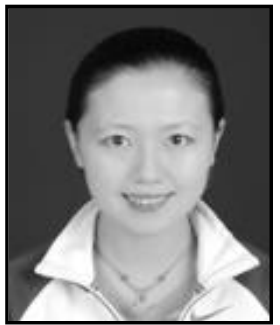

Wang Bei, Current position,grades:Sports Arts Department, Xi'an Physical Education University, Xi'an Shaanxi ,China Scientific interest:Sports Arts,Aerobics

Publications:More than 6 papers Published

Experience:She has Teaching Experience for more than 13 years and had completed 2 scientific research Projects 
International Journal of Future Generation Communication and Networking Online Vol. 9, No. 4, (2016) 